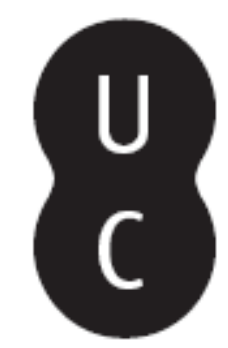

\title{
$\operatorname{inn} p$

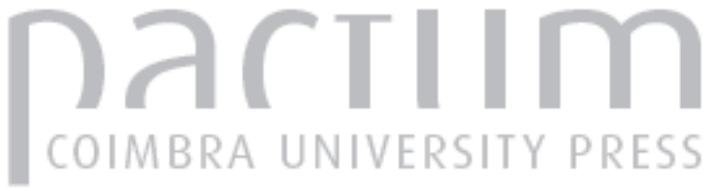

\section{[Recensão a] GONZÁLEZ HERRERO, Marta, Los caballeros procedentes de la Lusitania Romana. Estudio prosopográfico}

Autor(es): $\quad$ Andreu Pintado, Javier

Publicado por: Faculdade de Letras da Universidade de Coimbra

URL persistente:

URI:http://hdl.handle.net/10316.2/37760

DOI:

DOI:http://dx.doi.org/10.14195/1647-8657_46_17

Accessed : $\quad$ 26-Apr-2023 14:41:44

A navegação consulta e descarregamento dos títulos inseridos nas Bibliotecas Digitais UC Digitalis, UC Pombalina e UC Impactum, pressupõem a aceitação plena e sem reservas dos Termos e Condições de Uso destas Bibliotecas Digitais, disponíveis em https://digitalis.uc.pt/pt-pt/termos.

Conforme exposto nos referidos Termos e Condições de Uso, o descarregamento de títulos de acesso restrito requer uma licença válida de autorização devendo o utilizador aceder ao(s) documento(s) a partir de um endereço de IP da instituição detentora da supramencionada licença.

Ao utilizador é apenas permitido o descarregamento para uso pessoal, pelo que o emprego do(s) título(s) descarregado(s) para outro fim, designadamente comercial, carece de autorização do respetivo autor ou editor da obra.

Na medida em que todas as obras da UC Digitalis se encontram protegidas pelo Código do Direito de Autor e Direitos Conexos e demais legislação aplicável, toda a cópia, parcial ou total, deste documento, nos casos em que é legalmente admitida, deverá conter ou fazer-se acompanhar por este aviso.

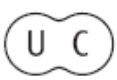




\section{CONIMBRIGA}

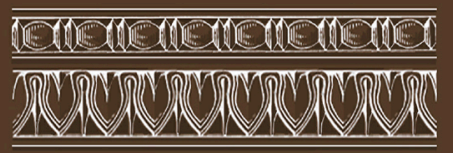

INSTITUTO DE ARQUEOLOGIA

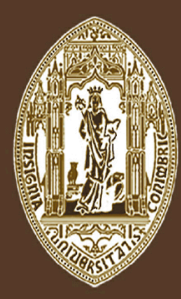

VOLUME XLVI - 2007

FACULDADE DE LETRAS UNIVERSIDADE DE COIMBRA 
En unas breves valoraciones expuestas al final del trabajo (p. 161-163) P. Reis apunta las principales conclusiones que ha ido exponiendo en los capítulos precedentes.

Como la propia autora expone en diversas partes del trabajo, son varios los aspectos no tratados de las instalaciones termales lusitanas como las características ornamentales de cada espacio y la evolución acontecida en la decoración interna de los edificios desde el siglo I al V d. C., los rasgos definitorios de cada estancia termal y los cambios planimétricos evidenciados en cada una de ellas a lo largo de estas centurias, las transformaciones funcionales (productivas, funerarias, domésticas o cultuales) que afectaron a las termas a partir de avanzado el siglo III d. C...

La obra se constituye como un catálogo actualizado de todas las termas hoy conocidas en la provincia Lusitania y una primera valoración general de un tema que adolecía de una enorme dispersión de los datos y al que la autora pretende dedicar ulteriores estudios que completarán los aspectos ahora no abordados o brevemente apuntados. El estado de abandono que preside buena parte de los edificios analizados y la antigüedad, en algunos casos, de las excavaciones que los exhumaron imposibilita en gran medida concretar más allá de lo que la autora lo ha hecho. Es este trabajo, por tanto, una importante herramienta de estudio para quien desee aproximarse al fenómeno termal en la provincia Lusitania.

Virginia García-Entero

GonZÁlez Herrero, Marta, Los caballeros procedentes de la Lusitania Romana. Estudio prosopográfico, Signifer Libros, Madrid, 2006, 127 páginas, ISBN: 84-933267-9-8.

Hace algunos años, a la salida del Instituto de Arqueología de la Universidad de Coimbra, un colega me aseguraba, convencido, el futuro que Lusitania tenía como objeto de atención investigadora de quienes nos dedicamos a la Historia Antigua Peninsular. No se equivocaba. En el tiempo que ha mediado desde aquel premonitorio aserto la prouincia Lusitania ha sido objeto de revisión en hasta siete mesas redondas, los Cuadernos Emeritenses del Museo Nacional de Arte Romano de Mérida se han ocupado de cuestiones clave para la mejor comprensión de la realidad de su capital (sirvan como ejemplo los trabajos de Ramírez Sádaba, J. L., Catálogo de las inscripciones imperiales de Augusta Emerita, Mérida, 2003; Pando, M. ${ }^{\mathrm{a}}$ T., La sociedad romana del conuentus Emeritensis a través de sus estelas funerarias, Mérida, 2005; o Edmonson, J., Granite Funerary Stelae from Augusta Emerita, Mérida 2007), las revistas Conimbriga, Anas, Humanitas, Revista Portuguesa de Arqueología, Studia Historica o Ficheiro Epigráfico - por citar las más difundidas - han seguido enriqueciendo el caudal de novedades sobre tan sin- 
gular territorio, el Grupo Mérida nos ha obsequiado con un excelente y útil atlas antroponímico (Grupo Mérida, Atlas Antroponímico de la Lusitania Romana, Mérida-Burdeos, 2003) y, más aún, nuevas generaciones de investigadores se han dejado seducir por el atractivo de los territorios ubicados entre el Duero, las fuentes del Tajo y el Guadiana.

Con un - como lo es el volumen en sí - muy seductor y acertadísimo prólogo del Prof. J. d'Encarnação - también decisivo protagonista de esta reivindicación de la Lusitania antigua, si podemos llamarla así - el trabajo Los caballeros procedentes de la Lusitania Romana - decimonovena entrega de una colección, Monografías y Estudios de Antigüedad Griega y Romana, de Signifer Libros que, en pocos años, se ha convertido en una de las de referencia entre lo mucho bueno que se publica sobre Antigüedad en nuestro país - constituye un hito más de esa fascinación lusitana a la que me vengo refiriendo. Y por muchas cosas. Marta González Herrero - que, en buena medida, se ha formado como investigadora en el Instituto de Arqueología de la Universidad de Coimbra y que es discípula del Prof. Julián de Francisco Martín (Francisco Martín, J. de., Conquista y romanización de Lusitania, Salamanca, 1996) - ha abordado, en primer lugar, una cuestión difícil, la de las elites sociales de Lusitania, dotadas de unas peculiaridades que hacen a aquéllas especialmente atractivas pero que, a la vez, las convierten en un conjunto de difícil aprehensión (Saquete, J. L., op. cit., p. 25). Se ha atrevido, además - y comparto la valoración que del resultado de dicho atrevimiento hace el Prof. J. d'Encarnação en el prólogo (p. 10) - con un corpus epigráfico de referencia nada cómodo y poco abundante - apenas alcanza la veintena de inscripciones - y, por último, ha sabido sintetizar de forma magistral (127 páginas para un tratado de prosopografía son, ciertamente, inauditas) en un tema oportuno que, hasta la fecha, apenas había sido tratado sólo por el siempre agudo y prolífico A. Caballos (Caballos Rufino, A., "Los equites y la dinámica municipal de Lusitania. I. Catálogo prosopográfico", en El proceso de municipalización en la Hispania Romana. Contribuciones para su estudio, Valladolid, 1998, pp. 205-233) - y en un área - la del ordo equester - en que se seguía dependiendo del igualmente excelente y siempre referido trabajo de J. M. Ojeda Torres (Ojeda Torres, J. M., El servicio administrativo imperial ecuestre en la Hispania Romana durante el Alto Imperio, Sevilla, 1993).

El resultado es una obra estructurada en tres grandes bloques, uno primero tal vez excesivamente sumario aunque en él Marta González Herrero remite a la bibliografía sobre el asunto, que, de hecho, demuestra dominar y que incorpora con una actualización digna de encomio y que afecta a cuestiones incluso tangenciales al asunto prosopográfico - en el que la autora procede a la caracterización de los modos de acceso al ordo equester y a desgranar someramente el significado de la dignitas equestris ordinis (pp. 11-17) -; otro central (pp. 23-89) en el que - dando continuidad a su excelente artículo de hace unos años: "Prosopografía de "praefecti fabrum' originarios de Lusitania”, Revista Portuguesa de Arqueologia, 7, 2004, pp. 365-384 y exhibiendo un infrecuente, y por ello meritorio, conocimiento de primera mano de la documentación epigráfica que lo centra - aborda el catálogo prosopográfico de referencia no sólo de los equites certi - algunos, singulares casos 
de las consecuencias de la extensión del ius Latii uniuersae Hispaniae (Plan. Nat. 3, 30), como M. Fidius Macer, de Capera (Stylow, A. U., "Apuntes sobre epigrafía de época flavia en Hispania", Gerión, 4, 1986, pp. 304) - sino también de otros sobre los que bien por las reservas que plantea la documentación epigráfica disponible sobre ellos bien por las peculiaridades de su cursus honorum es necesario catalogar todavía como equites incerti; y, por último, un último gran apartado (pp. 89-117) en el que la autora desgrana los elementos que, desde las caracterizaciones de referencia sobre este estamento de la sociedad romana (Pflaum, H. G., Les carrières procuratoriennes équestres sous l'Haut-Empire Romain, París, 1960-61) constituyen ejes fundamentales de su singularidad como tal, a saber: la origo, la riqueza y la ostentación de la misma, la existimatio pública recibida en el espacio urbano y su participación en las tareas administrativas provinciales. La estructura es acertada aunque la autora - con un también comprensible criterio de coherencia y proximidad y tal vez por exigencias editoriales - ha preferido introducir al respecto del catálogo prosopográfico reflexiones que bien podrían haber ido en el tercer bloque, lo que aleja su trabajo - que ello sea mérito o demérito corresponde al lector aseverarlo, en cualquier caso, es una obra utilísima - de los catálogos de prosopografía al uso (a modo de ejemplo, los trabajos de G. Alföldy, Flamines prouinciae Hispaniae Citerioris, Madrid, 1973 o Fasti Hispanienses. Senatorische Reichsbeamte und Offiziere in den spanischen Provinzen des Römisches Reiches von Augustus bis Diokletian, Weisbaden, 1969) y lo acerca a las nuevas síntesis sobre la sociedad romana a las que nos viene acostumbrado la historiografía más reciente (el trabajo arriba citad de Saquete, J. C., op. cit., sobre Augusta Emerita, podría ser un ejemplo).

Cualquiera de los temas que Marta González Herrero aborda - por ejemplo, los últimos citados al respecto de las últimas treinta páginas de su obra - habrían merecido una monografía específica tantas son sus implicaciones y tal es el interés que presentan (algunos, de hecho, han sido estudiados de ese modo: Andreu, J., La munificencia pública en la prouincia Lusitania, Zaragoza, 2004 o Gorges, J. G. (ed.), Sociedad y cultura en Lusitania Romana, Mérida, 2000). Ello convierte la obra que aquí comentamos en un excelente - a la vez ambicioso y útil - "estudio de conjunto" - como la autora lo llama (p. 17) - sobre los lusitanos que formaron parte del ordo equester. Gracias a él Marta González Herrero retrata dicho cuerpo social como poco implicado en el aparato político-administrativo provincial (pp. 109-110) - lo que no deja de ser original -, muy vinculado al cargo de praefectus fabrum y a las militiae (pp. 110-113), y con los habituales vínculos con sus comunidades de procedencia tanto a nivel de cursus honorum (pp. 113-117) como a nivel emotivo al volver sus ojos a ellas en la realización de sus actos de liberalitas (pp. 100-101) y en sus lazos familiares (pp. 93-95), actitud la primera que hemos constatado en otro lugar respecto de los munificentes lusitanos (Andreu, J., op. cit., p. 28) y que, de hecho, constituye un lugar común en los hábitos de las clases dirigentes romanas (Navarro, J., "El retorno a las ciudades de la aristocracia romana. Los senadores hispanos", en Elites y promoción social en la Hispania Romana, Pamplona 1999, pp. 165-167 o, con carácter general, y sobre un ámbito 
extra-hispano, Wesch-Klein, G., Liberalitas in Rem Publicam. Private Aufwendungen zugunsten von Gemeinden in römischen Afrika bis $284 \mathrm{n}$. Chr., Bonn, 1990, pp. 325-342). Se concluye, pues, en la presentación de un cuerpo social de elementos genuinos y con otros comunes al que éste exhibe en otras provincias (y que fueran recogidos por Demougin, S., (ed.), L'ordre équestre. Histoire d'une aristocratie (IIe sec. Av. J. C. - IIIe s. ap. J. C.), Roma, 1999) y es evidente que dicha caracterización debe llevarnos a todos a una más profunda reflexión sobre las peculiaridades de Lusitania como prouincia - primero - y sobre las de sus elites locales y provinciales - después - Tal vez resulte recurrente citar aquí el adagio latino que, según F. Millar (Millar, F., "Style Abides", JRS, 71, 1981, p. 152), presidía el fecundo trabajo de R. Syme: meditatio et labor in posterum ualescit. A buen seguro que Los caballeros procedentes de la Lusitania Romana. Estudio prosopográfico será un trabajo utilizadísimo y citadísimo pues, y no lo hemos señalado abiertamente hasta aquí, viene a llenar un vacío del que adolecía ya nuestra historiografía.

Destacados ya los indudables méritos, la oportunidad, el rigor y la solidez metodológica del trabajo de Marta González Herrero - que actualmente profesa en la Universidad de Oviedo - no quisiéramos cerrar esta valoración sin volver al prólogo que, como apuntamos, el Prof. J. d'Encarnação, de la Universidad de Coimbra, firma como pórtico del trabajo que aquí reseñamos. En él, con su habitual elegante pluma, el consumado epigrafista luso se interroga sobre la utilidad y estabilidad de la documentación epigráfica respecto de la tarea prosopográfica - los términos en que lo hace son, sencillamente, deliciosos (p. 10) - y advierte con acierto sobre el riesgo de sacralizarla. Como modesto conocedor de los entresijos de la dinámica municipal de Lusitania sólo puedo hacer una crítica - si es que así puede calificarse y no sería mejor llamarla, sencillamente, "advertencia" - al trabajo de Marta González Herrero: la contextualización. Es cierto que la Historia Antigua se escribe con y desde las fuentes y que es en ellas en las que descansa la exactitud que Tucídides reclamaba para la acción del historiador (Tuc. Hist. 1, 21), sin embargo, algunas de las conclusiones que la autora arroja - como la de que "la concesión del ius Latii no se tradujo en una intensificación de los ingresos en el ordo equester a partir del reinado de los Flavios" (p. 118) - deberían, entiendo, haber sido puestas en relación con lo que sobre dicha realidad nos está informando la epigrafía del resto de Hispania. Entiendo - y así lo he señalado en otro lugar (Andreu, J., "Edictum, municipium, y lex: la prouincia Lusitania en época Flavia (69-96 d. C.)", Conimbriga, 44, p. 143 - que promociones tan extraordinarias como la del Caperensis M. Fidius Macer permiten suponer que, a la larga, los municipios flavios - a los que la autora dedica un capítulo específico a partir de dos de sus más singulares ejemplos, no sólo a nivel provincial sino incluso hispano: la propia Capera y la ciuitas Igaeditanorum (pp. 90-92) - se convirtiesen - así sucedió, por ejemplo, en las controvertidas comunidades del Noroeste (Ortiz de Urbina, E., "La exaltación de la elite provincial. Los homenajes estatuarios decretados o autorizados por la prouincia Hispania Citerior", Epigraphica, 68, 2006, pp. 61-63) - en cantera de esa elite de homines noui e municipiis et colonias de la que hablan las fuentes (Tac. Dial. 8, 1-3) sino es que - como, ciertamente, invitan a pensar los 
datos que Marta González Herrero emplea (pp. 91-92) - Lusitania esté constituyendo un ejemplo del fracaso de la municipalización. Sea como fuere, quizás la conclusión podría haberse presentado de un modo más prudente aunque ya su sola constatación resulta, insisto, suficientemente meritoria y, a buen seguro, nos obligará a todos a valorar en su justa medida las peculiaridades de la documentación epigráfica de la más Vlterior de las prouinciae. En cualquier caso, si - como apuntamos más arriba a propósito del genial R. Syme - la madurez de un trabajo científico se mide en la intensidad con que interpela a quienes recurren a él en el futuro, es evidente que, por lo dicho hasta aquí y por lo que el lector habrá de descubrir, la obra de Marta González Herrero es sobradamente madura y digna heredera de los trabajos a los que esta joven investigadora - que, últimamente, se ha ocupado de cuestiones tan candentes como las del origen del culto imperial provincial en Lusitania (González Herrero, M., "La titulatura del flaminado provincial en las provincias hispanas", Epigraphica, 64, 2002, pp. 69-83) - nos había venido acostumbrando hasta la fecha. Como apuntamos más arriba, los lusitanistas contamos desde ya con un instrumento más para nuestra apasionante tarea. Estamos, pues, de enhorabuena.

Javier Andreu Pintado Universidad Nacional de Educación a Distancia - UNED 